\title{
Restorative proctocolectomy with ileal pouch-anal anastomosis for refractory or fulminant ulcerative colitis: Functional outcomes
}

\author{
Ali Mohamed El Anwar, MD; Hisham Adel, MD; Ahmed Nafae, MD; \\ Mohamed El-Shinawi, $M D$
}

\author{
Department of General Surgery, Ain Shams University, Cairo, Egypt.
}

\begin{abstract}
Background: Ulcerative colitis is a chronic inflammatory disease of the colon and rectum. During the course of their disease, about $30 \%$ of patients with ulcerative colitis (UC) will undergo proctocolectomy with ileal pouch-anal anastomosis (IPAA). Restorative proctocolectomy with IPAA is considered the procedure of choice for patients with UC requiring surgery.

Patients and methods: A prospective series of 20 patients from January 2004 till June 2008, presented with refractory or fulminant ulcerative colitis underwent restorative proctocolectomy with construction of J-pouch ileoanal anastomosis at Ain Shams University Hospitals and Ain Shams Specialized Hospital. The patients were 14 females (70\%) and 6 males (30\%) with an average age of $35.52 \pm 8.21$ years (range: $24-48$ ) years. Two-stage procedure was done in good risk patients while in high risk patients the three-stage procedure was adopted. The average follow up time was $34.21 \pm 15.32$ months (range: 12-60) months. All patients were studied one month after closure of ileostomy with evacuation pouchography to assess the function and efficiency of evacuation of the pouch. In our study, the primary aim was to assess the postoperative complications as well as the functional outcome following restorative proctocolectomy with Jpouch ileoanal anastomosis for ulcerative colitis.

Results: The average postoperative hospital stay was 23.52 \pm 8.56 days (range: 10-32) days. Only 2 patients (10\%) had the three-stage procedure, while 18 patients $(90 \%)$ had the two-stage procedure. The average follow up time was 34.21 15.32 months (range: 12-60) months. No intra or postoperative mortalities. Nine patients $(45 \%)$ had morbidities and all were managed conservatively. Six patients (30\%) developed variable degrees of wound infection and one patient (5\%) had minor anastomotic leak. Minor incontinence was recorded in 7 patients (35\%) and it was significantly improved in 5 of them during the first 12-18 months after closure of ileostomy. Anastomotic stricture developed in two patients (10\%), managed by repeated sessions of dilatation. Skin excoriation surrounding Ileostomy were found in four patients (20\%).Two patients (10\%) suffered from adhesive intestinal obstruction after closure of ileostomy. Recurrent pouchitis developed in six patients (30\%) and was controlled by metronidazole. The efficiency of the pouch evacuation was highly dependent on each of the pouch anal angles during rest and during straining. The final functional outcome was satisfactory in all patients.
\end{abstract}

\section{Introduction:}

Up to $30 \%$ of patients suffering from ulcerative colitis (UC) will ultimately need to undergo a total colectomy. ${ }^{1}$ The most frequent indications for colectomy include intractable disease and occurrence of dysplasia or cancer in case of long-standing colitis. A total proctocolectomy with ileal pouch-anal anastomosis (TPAA) has become the surgery of the definitive management of UC since it avoids a permanent stoma while removing all diseased colonic mucosa. ${ }^{2}$

Chronic ulcerative colitis has a bimodal distribution of incidence based on age, with a peak at 25 years and a second peak at 60 years. ${ }^{3}$

The aim of this procedure is to resect the entire large bowel (colon plus rectum) down to the dentate line, and to restore intestinal continuity through an ileo-anal anastomosis. ${ }^{2}$ This is a well established technique, which carries a minimal mortality $(<1 \%)$ but a 
significant morbidity (19-63\%). ${ }^{4}$ Short and long term results are good, with excellent scores of quality of life (QoL) and good functional results in many large series. ${ }^{5}$

Early reports of function after ileal pouchanal anastomosis (IPAA) for chronic ulcerative colitis (CUC) have indicated favorable outcomes, with an excellent quality of life for more than $90 \%$ of patients. ${ }^{4}$

The primary aim of our study was to assess the postoperative complications as well as the functional outcome of restorative proctocolectomy with IPAA in patients with ulcerative colitis.

\section{Patients and methods:}

A total of 20 consecutive restorative proctocolectomy with construction of J-pouch ileoanal anastomosis were performed at Ain Shams University Hospitals and Ain Shams Specialized Hospital in the period from January 2004 till June 2008 in patients presented with refractory or fulminant ulcerative colitis. The patients were 14 females (70\%) and 6 males $(30 \%)$ with an average age of $35.52 \pm 8.21$ years (range: 24-48) years. The average weight was $50.5 \pm 13.22 \mathrm{Kg}$ (range: 40-65).

The most common presenting symptoms were passage of blood and mucus per rectum, diarrhea, frequency, urgency, incontinence, loss of weight and general ill health. All patients had panproctocolitis that was diagnosed by colonoscopy and/or barium enema and biopsy Figure(1).

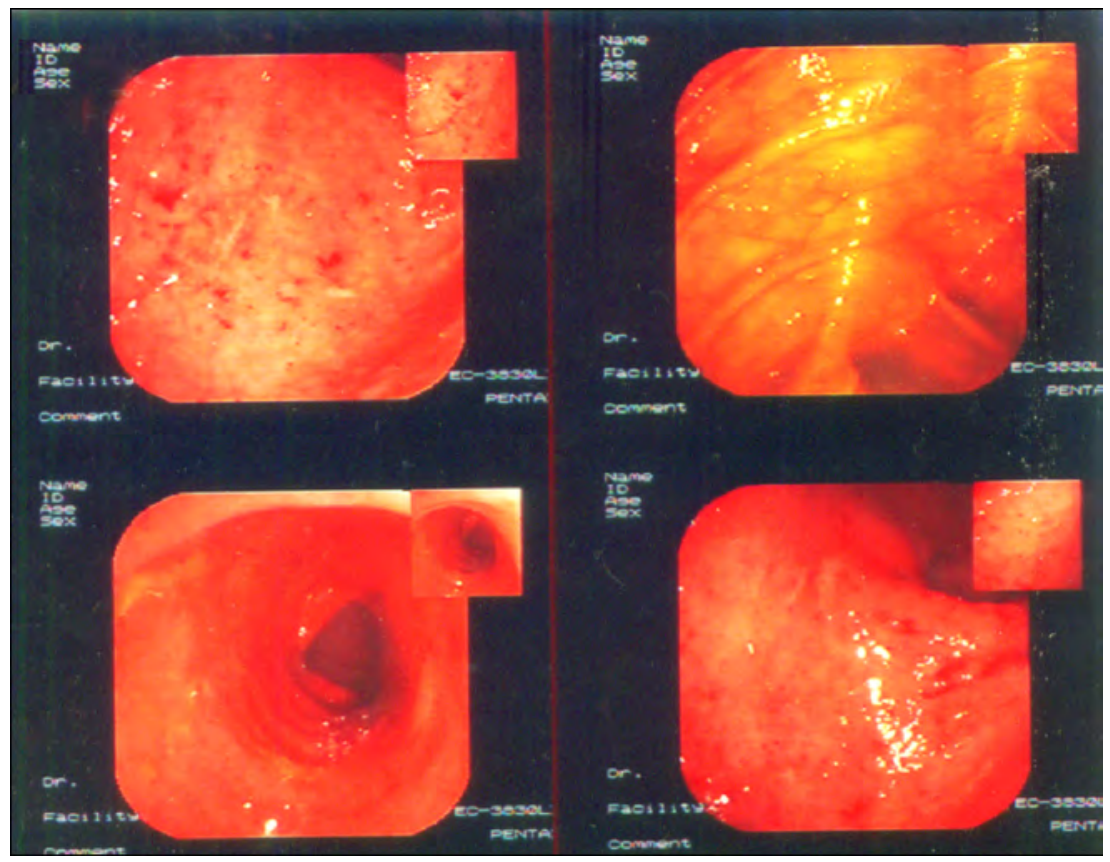

Figure (1): Colonoscopy pictures of ulcerative colitis.

Two-stage procedure was done in good risk patients while in high risk patients the threestage procedure was adopted. The operation entailed resection of the whole colon and rectum to the top of the anal canal and construction of a pouch from the terminal ileum that was anastomosed to the anal canal.

The two stage operation consisted of total proctocolectomy, pouch construction, pouch anal anastomosis and covering loop ileostomy in the first stage with loop ileostomy closure in the second stage.

The three-stage procedure was done in frail patients with advanced disease who could not withstand a major procedure in the first stage. Preoperative preparation by IV fluids, blood transfusion, TPN and IV steroids. Total colectomy with terminal ileostomy followed by second stage proctectomy, pouch construction, pouch anal anastomosis and covering loop ileostomy. Closure of the loop ileostomy in the third stage.

The ileal pouch in all patients was of the $\mathrm{J}$ type. Pouch construction and pouch anal anastomosis were all stapled.

All patients had the configuration and function of their pouches examined one month after closure of ileostomy by evacuation pouchography. The average follow up time was 34.21 15.32 months (range: 12-60) months. 


\section{Surgical technique: Figure(2)}

The colon was fully mobilized taking care to preserve the greater omentum when mobilizing the transverse colon. The appropriate vessels were ligated and divided taking care to preserve the ileocolic vessels. The terminal ileum was divided using GIA 50 stapler. The pelvis was entered in the Holly plane to full mobilize the rectum with complete preservation of the pelvic autonomic nerves. Dissection extended until the pelvic floor was

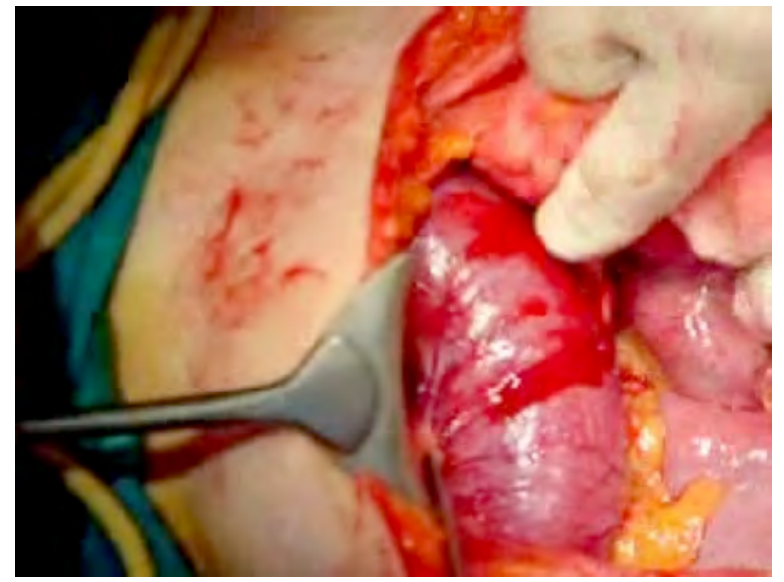

(A) Fiery red sigmoid colon.

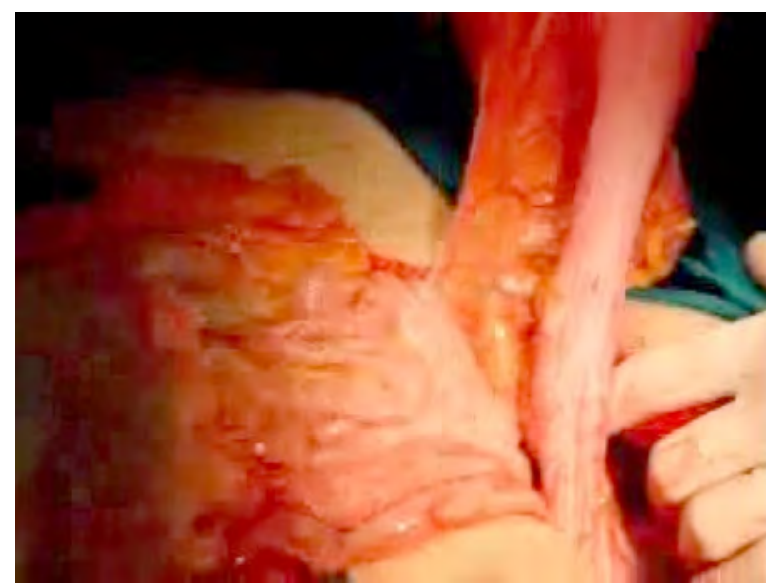

(C) Mobilization of the left colon. reached and the rectum narrowed to form the anal canal. A transverse rectal clamp (previously roticulator 55 then contour) was applied at the anorectal junction. An assistant inserted the index finger from the anus to assess the length of the remaining anal canal stump which should be 3 to $4 \mathrm{~cm}$. If a longer stump was left, further mobilization was done until the entire rectum was mobilized till the top of the anal canal. The rectum was then divided and the specimen was removed.

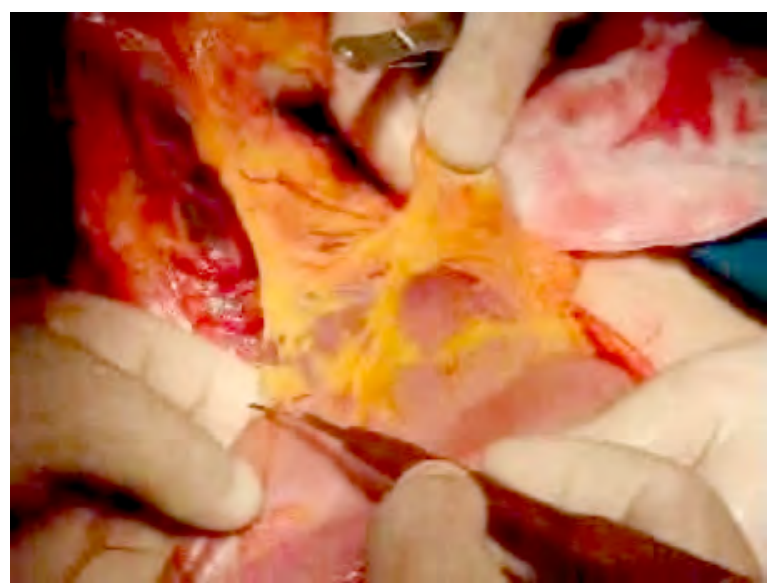

(B) Mobilization of transverse colon.

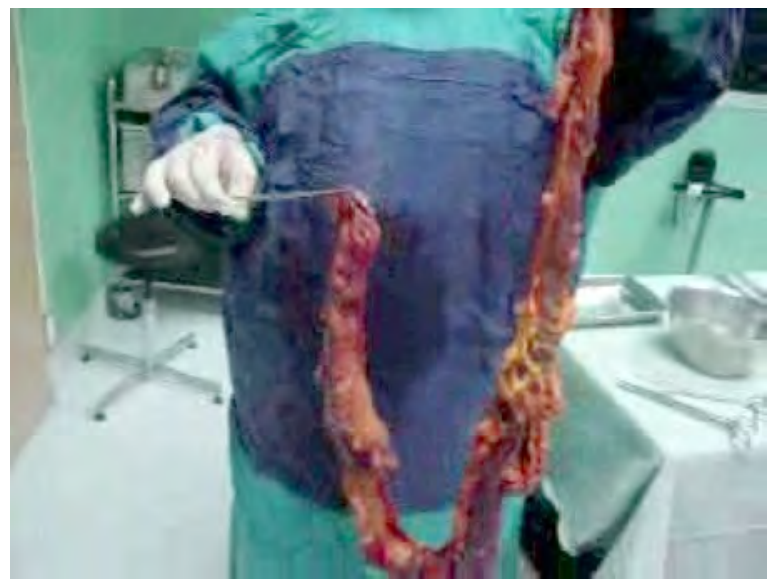

(D) The whole colon removed.

Figure (2)

\section{Pouch construction: Figure(3)}

A $20-\mathrm{cm} \mathrm{J}$ pouch was constructed from the terminal ileum. Before starting construction of the pouch, its apex was tested to reach the bottom of the pelvis so that anastomosis with the top of the anal canal could be done without tension. Transverse peritoneal incisions and division of some mesenteric attachments and some unimportant vessels can add extra length to the pouch. Each limb of a GIA instrument was introduced in a limb of the $\mathrm{J}$ pouch via a stab wound at the apex of the pouch. The pouch was constructed by two applications of GIA 90 or three applications of GIA 50. A one hundred and fifty $\mathrm{ml}$. saline was injected via a Foley catheter into the pouch to test its integrity and capacity. Any leaking point was reinforced by stitches. 

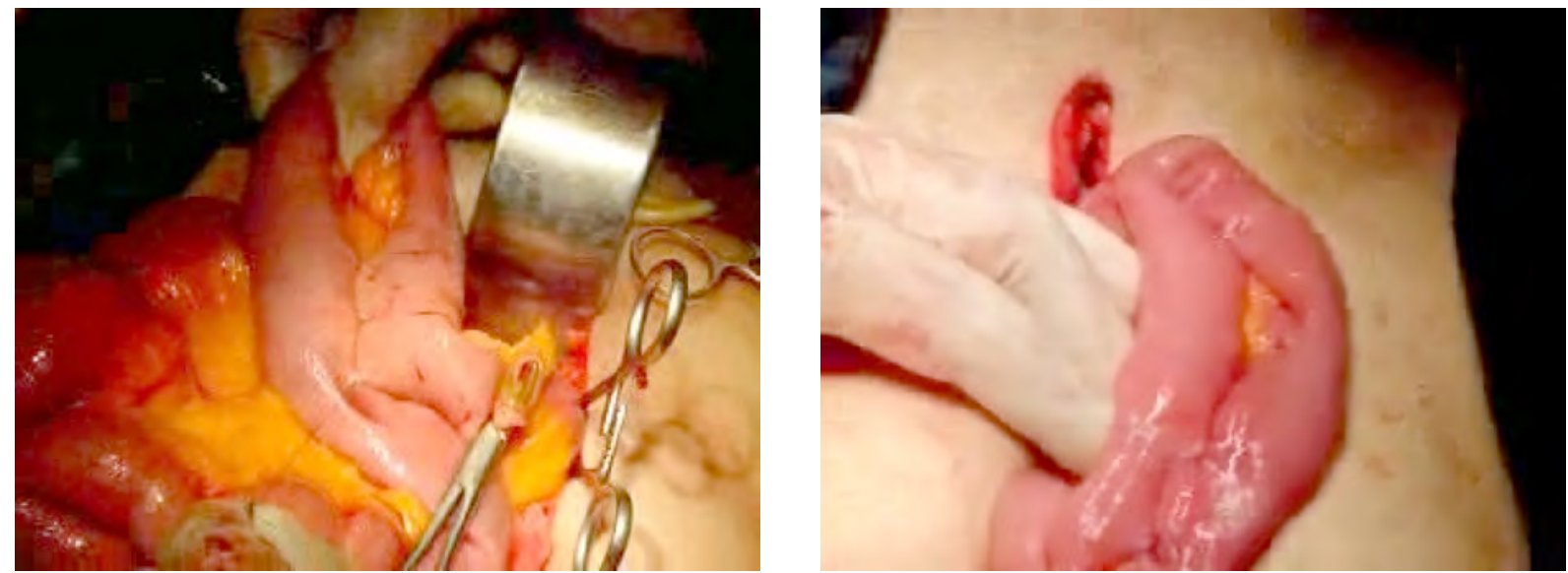

(A) Few interrupted sutures for anterior layer.
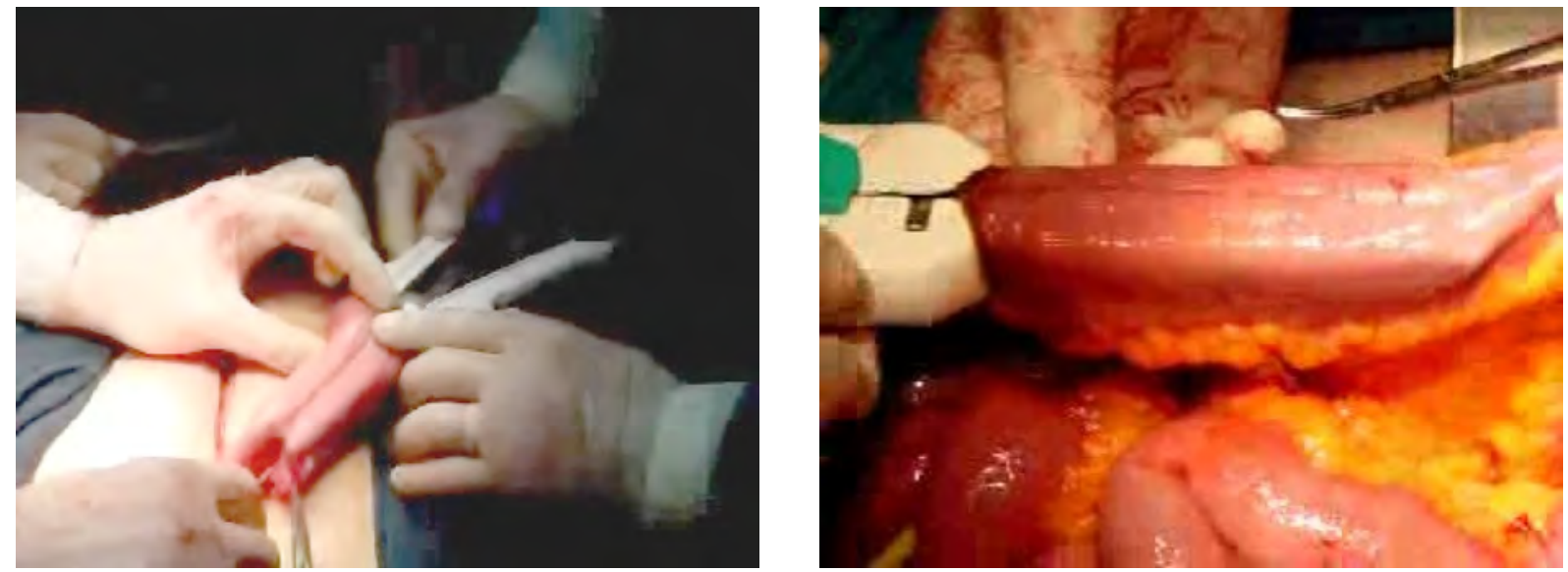

(B) GIA 90 stapler constructing the pouch.

Figure (3)

Pouch anal anastomosis: Figure(4)

The shaft of premium-CEEA 31 stapler was inserted from the anus and the screw at the distal end of the shaft was rotated to advance the central pin until it pierced the transverse staple line of the anal canal stump. The anvil of the instrument was introduced in the pouch through the opening at its apex that was used beforehand for inserting the GIA instrument.

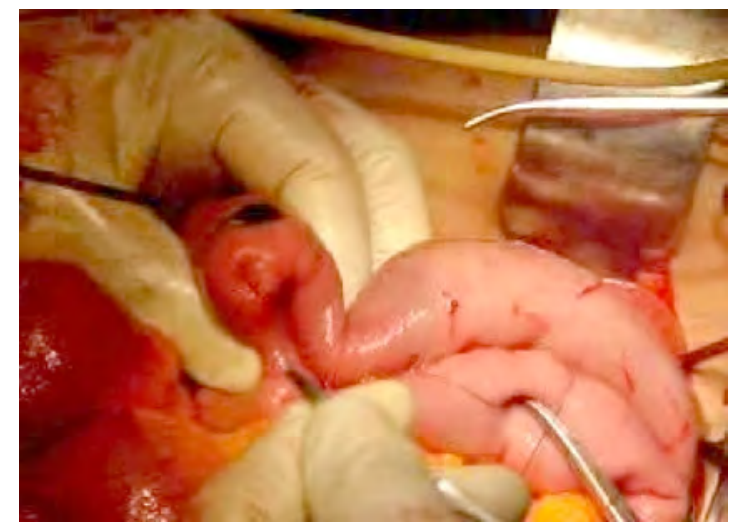

(A) Stab wound at the apex of the pouch.
A purse string suture using prolene $2 / 0$ was taken and tied to secure the pouch around the rod of the anvil. The anvil was then fixed to the central rod of the shaft and the screw at the distal end of the shaft was rotated to approximate the bowel ends. The instrument was fired, extracted and the doughnuts were examined to make sure they were complete.

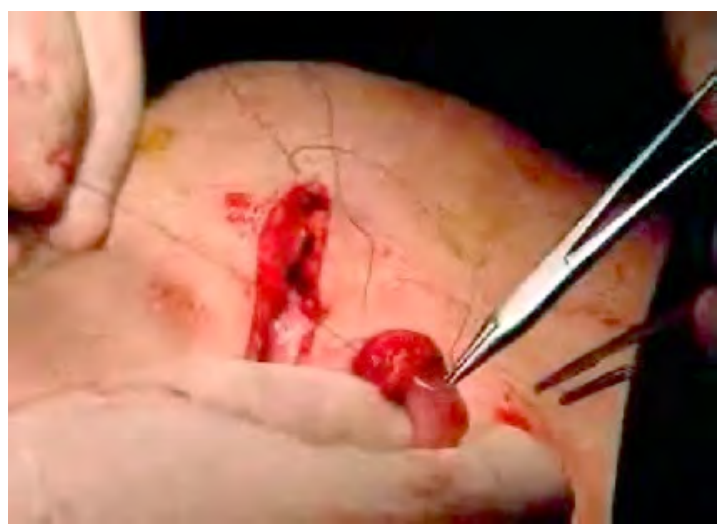

(B) Purse string application. 


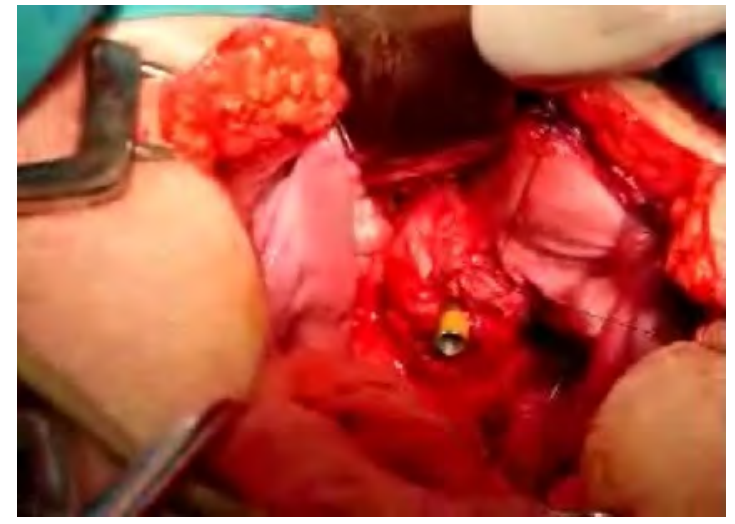

(C) Anvil insertion.

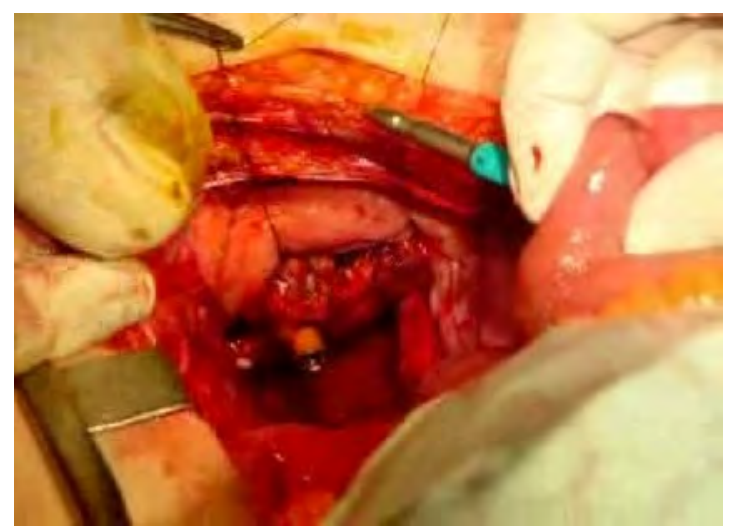

(E) Rod of CEEA 31 stapler introduced through the anal canal stump inserted into the anvil.

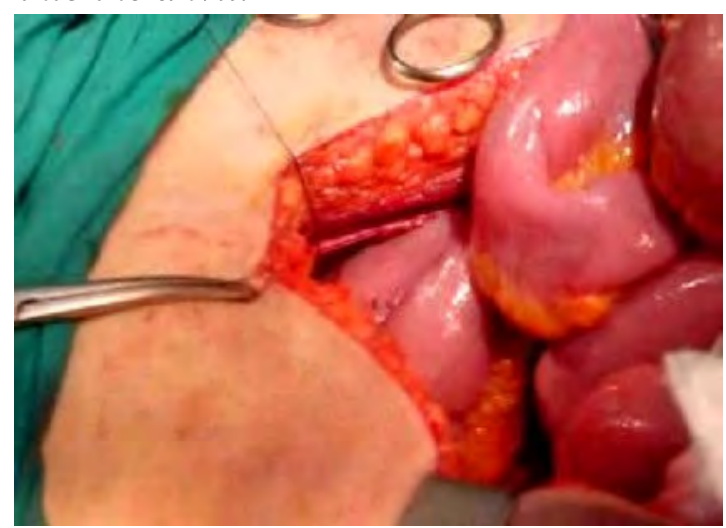

(G) Pouch-anal anastomosis was completed.

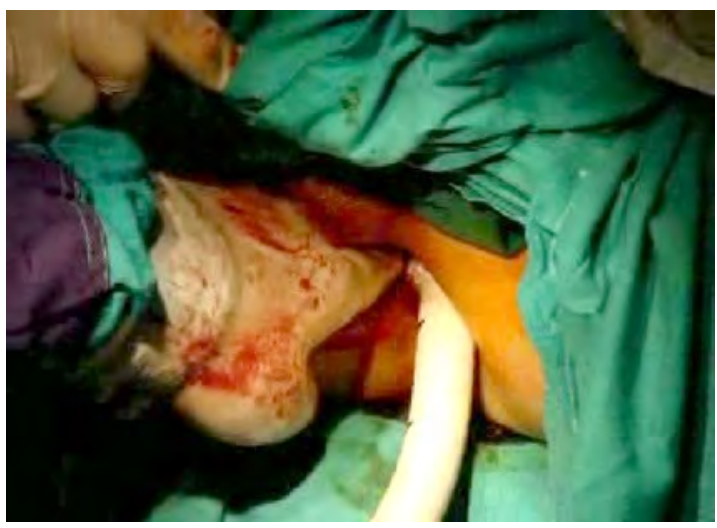

(D) CEEA 31 stapler introduced through the anal orifice.

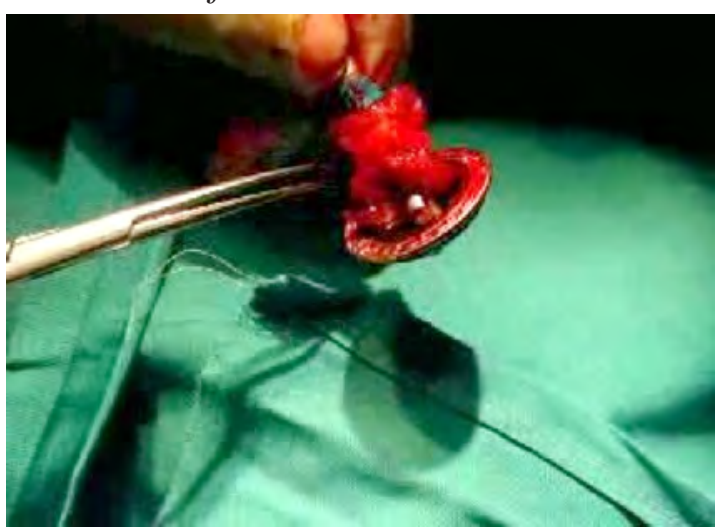

(F) Two complete doughnuts of the purse string.

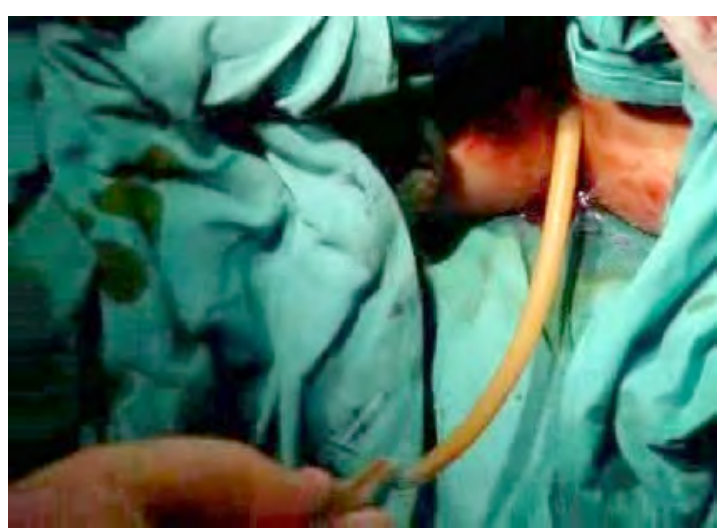

(H) Testing the pouch integrity.

Figure (4)

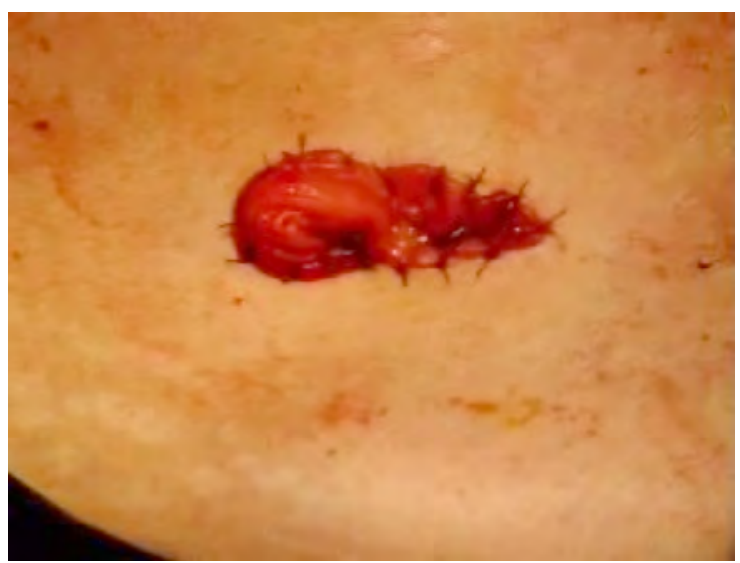

Figure (5): Loop ileostomy. 
A covering loop ileostomy was done at the end of the operation Figure(5) and suction drain was left in the pelvis. Closure of the temporary ileostomy was always preceded by a digital and radiographic examination of the ileoanal anastomosis and the pouch to assess patency and integrity.

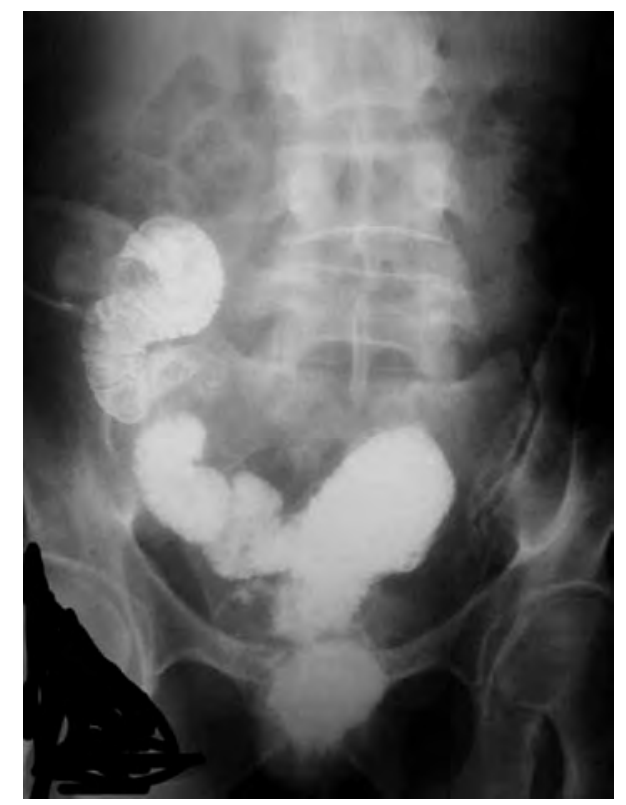

Figure (6): Postoperative pouchography showing no leak with patulous pouch-anal anastomosis.

\section{Results:}

The patients were 14 females (70\%) and 6 males (30\%) with an average age of $35.52 \pm 8.21$ years (range: 24-48) years. The average postoperative hospital stay was $23.52 \pm 8.56$ days (range: 10-32) days. The length of the stay was significantly affected by the occurrence of septic complications (average $12.31 \pm 1.54$ days without septic complications versus $32.69 \pm 7.55$ days with septic complication). Only 2 patients $(10 \%)$ had the three-stage procedure, such patients were found in a very bad general condition at presentation, while 18 patients $(90 \%)$ had the two-stage procedure. Both procedures were performed with no intraoperative or postoperative mortality. The average follow up time was 34.21 115.32 months (range: 12-60) months.
Evacuation pouchography was performed routinely one month after closure of ileostomy. Four basic films were taken to document the process of defecation: resting, squeezing, straining and defecation. Data looked for in the films were: lie of the pouch in the pelvis, pouch anal angle during rest, squeeze and strain and any abnormal pouch morphology Figures(6,7).

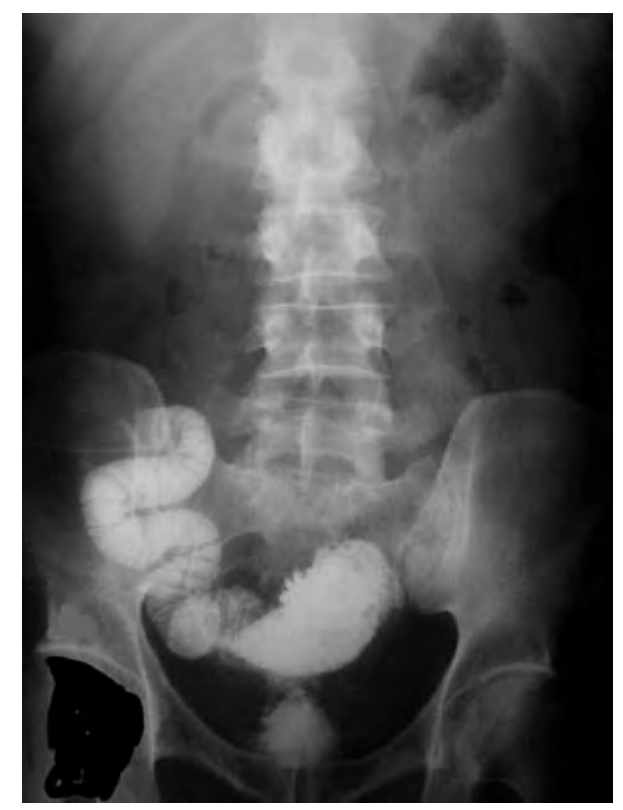

Figure (7): Postoperative pouchography showing vertical lie of the pouch in the pelvis.

Nine patients (45\%) developed 21 different complications Table(1). All patients who developed sepsis were controlled by conservative treatment. Six patients had wound infection varying from mild to severe, however, one patient had minor pelvic sepsis due to minor anastomotic leak. Anastomotic stricture developed in two patients $(10 \%)$, responded to repeated sessions of dilatation. Skin excoriation surrounding ileostomy were found in four patients $(20 \%)$. Two patients $(10 \%)$ suffered from adhesive intestinal obstruction after closure of ileostomy and both were managed conservatively. Recurrent pouchitis developed in six patients $(30 \%)$ and was controlled every time by a short course of metronidazole. 
Table (1): Postoperative morbidity.

\begin{tabular}{|l|c|c|}
\hline Morbidity & Number & \% \\
\hline Wound sepsis & 6 & 30 \\
\hline Minor leak & 1 & 5 \\
\hline Pouch necrosis & 0 & 0 \\
\hline Pouch-anal anastomosis stricture & 2 & 10 \\
\hline Ileostomy related complications & 4 & 20 \\
\hline Adhesive intestinal obstruction & 2 & 10 \\
\hline Pouchitis & 6 & 30 \\
\hline
\end{tabular}

\begin{tabular}{|ll|}
\hline$\square$ Wound sepsis & $\square$ Minor leak \\
$\square$ Pouch-anal anastomosis stricture & $\square$ lleostomy related complications \\
$\square$ Adhesive intestinal obstruction & $\square$ Pouchitis \\
\hline
\end{tabular}

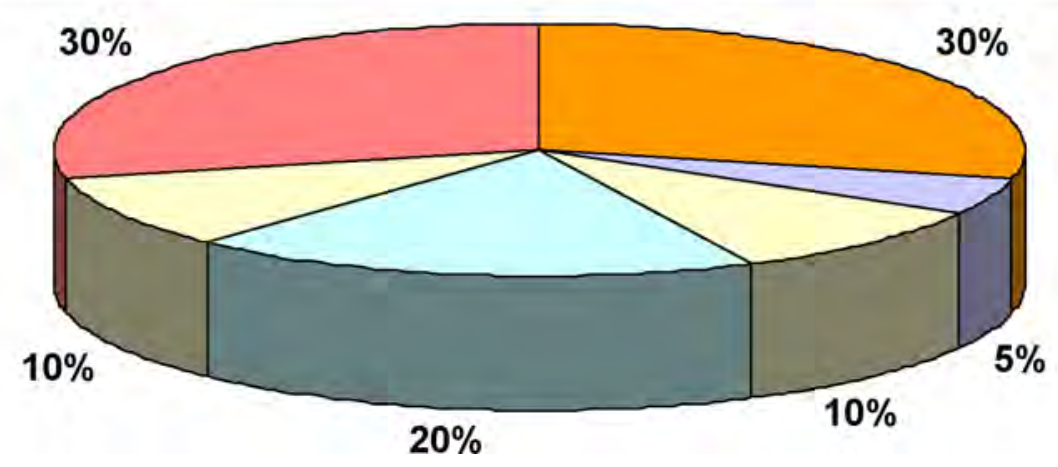

Figure (8): Postoperative Morbidity.

\section{Disease control: Table(2)}

During the follow up period (range: 12-60) months, all patients showed variable degrees of improvement in their health and having sense of well being with increased ability to work. The weight gain (range:12-35 Kg) was noticed in all patients with nearly normalization of hemoglobin, albumin and ESR levels.

Table (2): Objective parameters of postoperative improvement.

\begin{tabular}{|c|c|c|c|c|}
\hline \multirow{2}{*}{ Parameter } & \multirow{2}{*}{$\begin{array}{l}\text { Preoperative } \\
\text { Mean (range) }\end{array}$} & \multirow{2}{*}{$\begin{array}{l}\text { Postoperative } \\
\text { Mean (range) }\end{array}$} & \multicolumn{2}{|c|}{ Paired t-test } \\
\hline & & & t & P-value \\
\hline \multirow{2}{*}{ Weight (kg) } & $(45-65)$ & $(59-110)$ & \multirow{2}{*}{52.666} & \multirow{2}{*}{$<0.001 *$} \\
\hline & $50.5 \pm 13.22$ & $84.93 \pm 12.44$ & & \\
\hline \multirow{2}{*}{$\operatorname{Hemoglobin}(\mathrm{gm} / \mathrm{dl})$} & $(6.2-10.1)$ & $(8.9-14.5)$ & \multirow{2}{*}{2.351} & \multirow{2}{*}{$0.034^{*}$} \\
\hline & $8.2 \pm 1.26$ & $11.54 \pm 2.87$ & & \\
\hline \multirow{2}{*}{ Albumin (gm/dl) } & $(2.2-4.1)$ & $(3.4-4.6)$ & \multirow{2}{*}{2.11} & \multirow{2}{*}{0.046} \\
\hline & $3.32 \pm 0.728$ & $4.13 \pm 0.41$ & & \\
\hline \multirow{2}{*}{ ESR (mm/hour) } & $33(17-59)$ & $11(7-14)$ & \multirow{2}{*}{23.454} & \multirow{2}{*}{$<0.001 *$} \\
\hline & $35.94 \pm 14.66$ & $11.46 \pm 2.33$ & & \\
\hline
\end{tabular}

*Significant at P-value $<0.05$. 


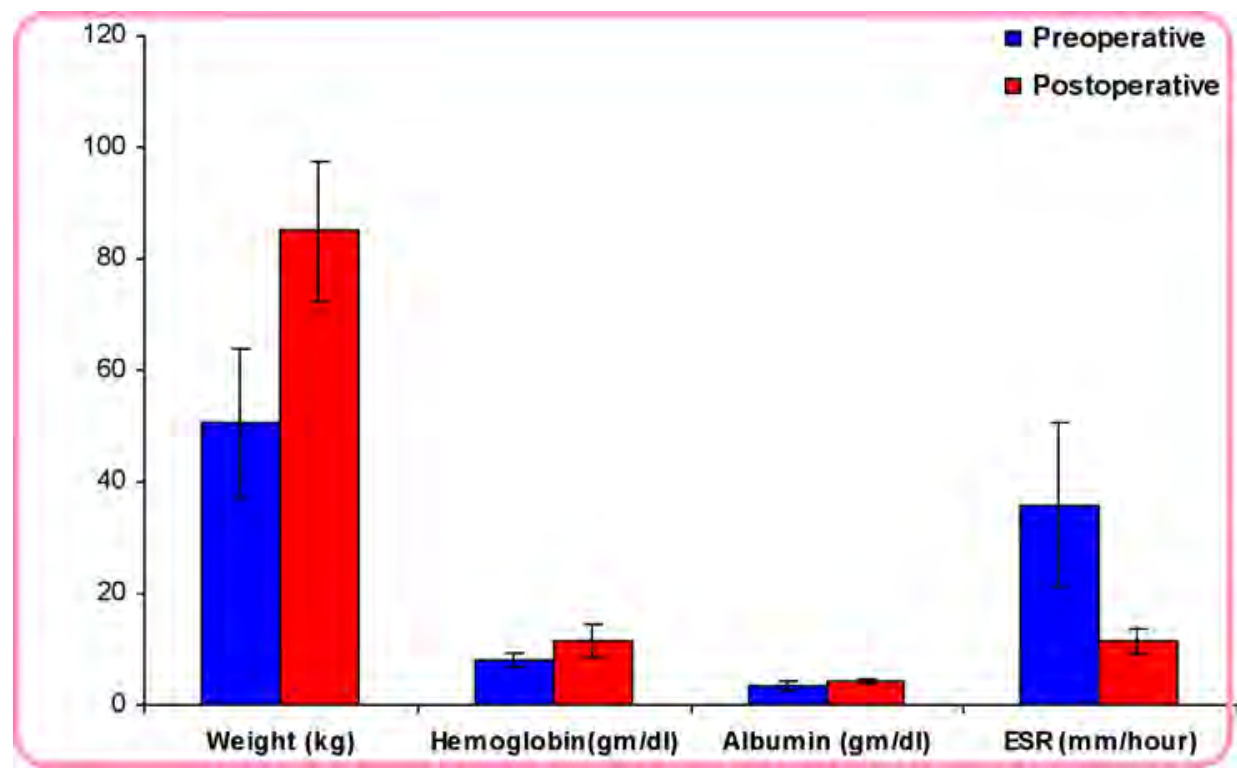

Figure (9): Objective parameters of postoperative improvement.

Functional outcome and patients' satisfaction: Table(3).

Table (3): Functional outcome and patients' satisfaction.

\begin{tabular}{|c|c|c|c|c|}
\hline & \multirow{2}{*}{$\begin{array}{l}\text { Two Months } \\
\text { (after } \\
\text { ileostomy } \\
\text { closure) }\end{array}$} & \multirow{2}{*}{$\begin{array}{l}\text { Six Months } \\
\text { (after } \\
\text { ileostomy } \\
\text { closure) }\end{array}$} & \multicolumn{2}{|c|}{ Test } \\
\hline & & & $\begin{array}{c}\text { Statistical } \\
\text { value }\end{array}$ & $P$-value \\
\hline $\begin{array}{l}\text { Frequency of bowel movement } \\
\text { per } 24 \text { hours [median(range)] }\end{array}$ & $8(5-11)$ & $7(4-10)$ & $\mathrm{Z}=0.52$ & 0.881 \\
\hline $\begin{array}{l}\text { Diurnal bowel movement } \\
\text { [median(range)] }\end{array}$ & $6(4-8)$ & $5(3-8)$ & $\mathrm{Z}=0.932$ & 0.25 \\
\hline $\begin{array}{l}\text { Nocturnal bowel movement } \\
\text { [median(range)] }\end{array}$ & $2(1-3)$ & $1(0-2)$ & $\mathrm{Z}=1.055$ & 0.09 \\
\hline $\begin{array}{l}\text { Ability to postpone a bowel } \\
\text { movement until convenient } \\
\text { [no. of patients }(\%)]\end{array}$ & $14(70 \%)$ & $18(90 \%)$ & $X^{2}=1.406$ & 0.2357 \\
\hline $\begin{array}{l}\text { Ability to distinguish flatus from } \\
\text { stool [no. of patients (\%)] }\end{array}$ & $16(80 \%)$ & $19(95 \%)$ & $X^{2}=0.914$ & 0.3390 \\
\hline $\begin{array}{l}\text { Sensation of incomplete } \\
\text { evacuation of the pouch } \\
\text { [no. of patients }(\%) \text { ] } \\
\text {-Never } \\
\text {-Sometimes } \\
\text {-Often } \\
\text {-Always }\end{array}$ & $\begin{array}{l}4(20 \%) \\
8(40 \%) \\
4(20 \%) \\
2(10 \%)\end{array}$ & $\begin{array}{l}7(35 \%) \\
10(50 \%) \\
2(10 \%) \\
1(5 \%)\end{array}$ & $X^{2}=1.941$ & 0.584 \\
\hline
\end{tabular}




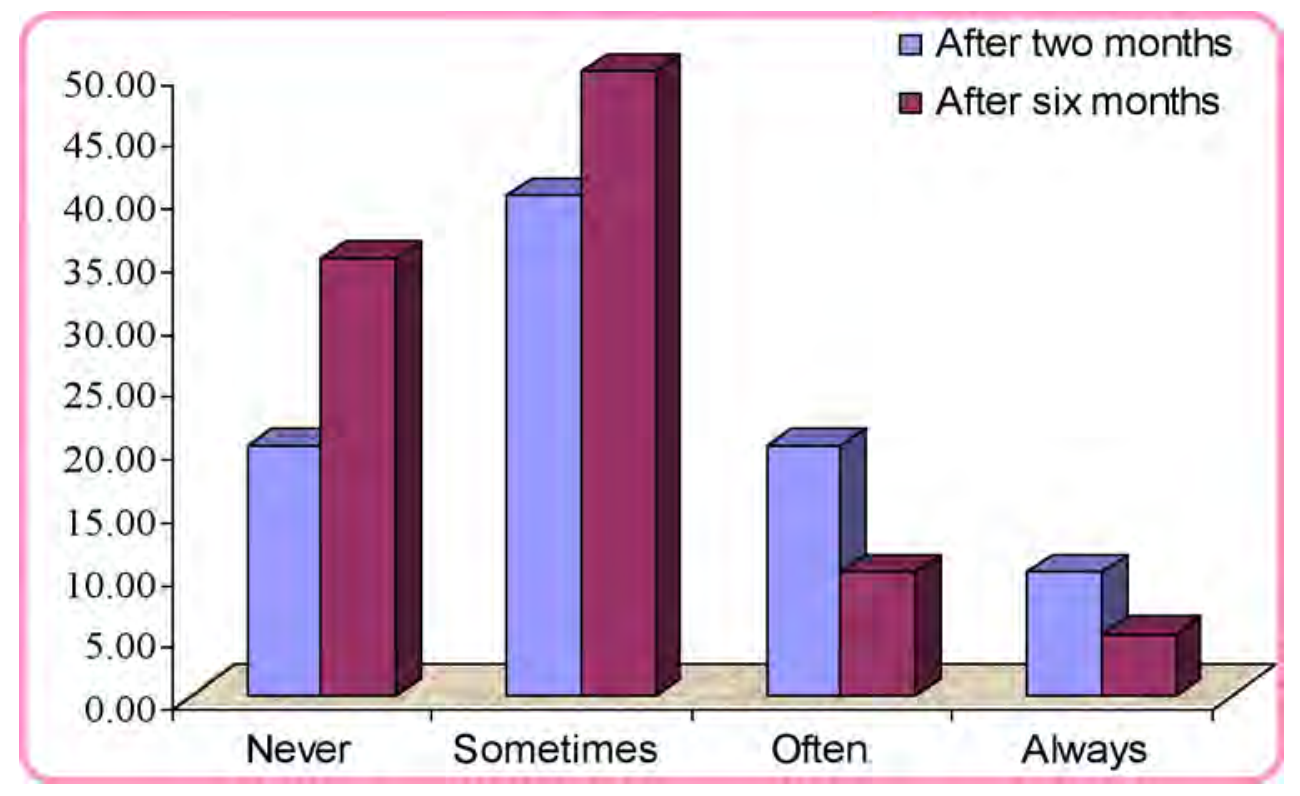

Figure (10): Functional outcome and patients' satisfaction.

Efficiency of pouch evacuation:

We found a positive correlation between the efficiency to evacuate the pouch and the resting pouch anal angle, the pouch anal angle during straining and the increment in pouch anal angle as a result of straining. Reviewing the pouch graphic picture gave us the impression that the more vertical the lie of the pouch in the pelvis is the better is the function Figures(6,7).

\section{Discussion:}

The restorative proctocolectomy with ileal pouch anal anastomosis has become the procedure of choice for the surgical treatment of patients with ulcerative colitis. ${ }^{6}$ The aim of this procedure is to resect the entire large bowel (colon plus rectum) down to the dentate line, and to restore intestinal continuity through an ileo-anal anastomosis. ${ }^{4}$

In experienced hands, the complication rate has been less than $30 \%$ and the majority of patients will experience good long-term pouch function. ${ }^{7}$ A percentage of these patients, however, will develop a variety of complications that can be in large part managed conservatively. ${ }^{8}$

In our series nine patients (45\%) developed 21 different complications $\operatorname{Table(1).~In~the~}$ series carried out by Wutbrich et al. ${ }^{9}$ the global rate of complications was $65 \%$.
All patients who developed sepsis $(\mathrm{n}=7)$ (35\%) were controlled by conservative treatment. In the series carried by Marc Ferrante et al. ${ }^{10}(25 \%)$ of patients had septic complications with $(10 \%)$ had minor leak and all were managed conservatively.

Anastomotic stricture developed in two patients $(10 \%)$, all of them responded to repeated sessions of dilatation and this goes with the study carried by Wutbrich et al. ${ }^{9}$ where the most frequent pouch related complications were anastomotic strictures (14\%). Gina et al. ${ }^{11}$ also reported stricture at the pouch anal anastomosis to be $10.3 \%$.

Two patients (10\%) suffered from adhesive intestinal obstruction after closure of ileostomy and both were managed conservatively. This is in accordance with the results of a recent meta analysis $(5,853$ cases of IPAA) showing a $(13 \%)$ incidence of small bowel obstruction. ${ }^{12}$

Pouchitis is a late complication of ileal pouch-anal anastomosis and should be suspected in any patient who experiences abdominal cramps, increased stool frequency, watery or bloody diarrhea, and flu like symptoms. Although many patients are treated on clinical grounds alone, accurate diagnosis requires endoscopic visualization of the pouch, as well as histological evaluation. ${ }^{13}$

In the past, several investigators reported that most of the pouchitis episodes occur only once in a patient and can be treated successfully 
with antibiotics, with chronic pouchitis in only $5 \%$ of patients. ${ }^{14}$ In contrast Shen et al. ${ }^{15}$ observed that $60 \%$ of patients with pouchitis developed acute relapsing or chronic pouchitis.

In a multivariate analysis, patients developing pouchitis during follow up were significantly younger at closure of ileostomy and more often had preoperative extra intestinal manifestations. ${ }^{15}$ However, one should bear in mind that different investigators might have used different diagnostic criteria, different satisfaction of pouchitis, and different intensity and duration of follow up. ${ }^{15}$

In our study, recurrent pouchitis developed in six patients (30\%) and was controlled every time by a short course of metronidazole. Such observation lends support to the theory that interaction between pouch bacteria levels and the mucosal immune system plays an important role in pathogenesis of pouchitis. ${ }^{16}$ In our study, age was not proved to be a risk factor influencing the incidence of pouchitis. On the other hand, patients presented with preoperative extra intestinal manifestations were likely to develop pouchitis.

In our study, we noticed that stool frequency was significantly decreased at 2 months after closure of the ileostomy into an average 6 diurnal bowel movements and one nocturnal bowel movement. This goes with the study carried by Michelassi et al. ${ }^{17}$ who noticed that median stool frequency was 7 in a 24-hour period at both 1 year and 10 years. Wutbrich et al. ${ }^{9}$ stated that only $27 \%$ of patients have never been disturbed at night and $65 \%$ of patients have 5 to 10 bowel movements per day. Patients who are candidates for reconstructive proctocolectomy should receive adequate information preoperatively and be aware that, while the control of bowel movements is good during daytime, this procedure is associated with night time bowel movements and soiling in a significant percentage of cases. Mathis et al. ${ }^{18}$ reported 5 daytime (range, 3-12), and 1 nighttime (range, 0 6) bowel movements.

Incontinence is very likely because of the semisolid nature of the pouch contents, the diminished compliance of the pouch as compared to the normal rectum and the compromised sphincter function resulting from the inevitable dilatation of the sphincter during performing the pouch anal anastomosis. ${ }^{19} \mathrm{In}$ the study carried by Wutbrich et al. ${ }^{9}$ none of the patients reported true fecal incontinence during the day, but $17 \%$ had some degree of incontinence to gas, $31 \%$ reported occasional soiling and $35 \%$ regularly used a perineal pad. At night continence was excellent in $41 \%$ of patients, 34\% reported minor episodes of incontinence to loose stools and $24 \%$ complained of soiling. In the study carried by Mathis et al., ${ }^{18}$ day time incontinence was occasional in $43 \%$ and frequent in $4 \%$. Nighttime incontinence was occasional in 54\% and frequent in $7 \%$ while $62 \%$ reported no problems discerning flatus from feces.

In our study, mild incontinence in the form of fecal staining of the under clothes developed in seven patients immediately after closure of ileostomy (35\%), however this is improved spontaneously by time in five patients. Major incontinence was not encountered in any of our patients. We noticed that when incontinence was present, it improved spontaneously over time. The improvement was most significant during the first 12-18 months, suggesting that it parallels the disappearance of the local response to the trauma of surgery on the anal sphincter and the patient's adaptation to the procedure.

Ileostomy related complications were found in four patients $(20 \%)$, all patients had skin excoriation.

Living with a stoma has been shown to be associated with definite psychological problems and ileostomy has been associated with technical complications in up to $57 \%$ of patients, some authors believe that one stage totally stapled restorative proctocolectomy without covering ileostomy in elective situations, would avoid ileostomy related complications without any increase in anastomotic complications. ${ }^{20}$ Grofine et al., ${ }^{21}$ strongly supported avoidance of loop ileostomy. In their nonrandomized comparison, the laparotomy rate for small bowel obstruction was reduced from $10 \%$ to $1 \%$, but leak rates and sepsis were comparable. However, Tjandra et al. ${ }^{22}$ at the Cleveland clinic strongly defended their policy of pouch diversion, reporting that rates of ileoanal anastomotic leakage and pelvic 
sepsis were only $4 \%$ in the defunctioned group compared with $14 \%$ when loop ileostomy was not used. Gina et al. ${ }^{11}$ supports the use of a protective ileostomy in view of the improvement in short term outcomes, particularly sepsis. However, the omission of a covering ileostomy may still be justified in patients defined as low risk. The definition of low risk is a point for further discussion and quantitative analysis.

In our study, all patients were subjected to a temporary covering ileostomy in order to protect the newly constructing pouch and pouch anal anastomosis. We noticed that ileostomy related complications were either temporary or minor and were successfully treated by conservative management.

The primary goal of the operation is to eradicate the disease, at a low mortality and morbidity with good functional outcome and good quality of life. In our study, we achieved many of such goals as we did not encounter any mortality and eradication of the disease was achieved in all patients. The latter was proved by the improvement in health, weight gain and restoration of normal blood investigations.

Emptying of pelvic intestinal reservoirs varies greatly; in general, pouches are less efficient in evacuation than the normal rectum. Nasmyth and colleagues ${ }^{23}$ found that normal controls expelled $99 \%$ of rectal contents in a single act of defecation, whereas patients with ileal reservoirs retained on average $15-30 \%$ of contents of reservoirs. In our study, we achieved very good efficiency of pouch emptying and this is probably because all our pouches were of the $\mathrm{J}$ type.

It has been shown that $\mathrm{S}$ pouches are less efficient in emptying than $\mathrm{J}$ or $\mathrm{W}$ pouches because of the presence, in the former, of a long efferent limb which is predisposed to angulations and kinking during straining making it difficult for the patient to empty. It is known that $S$ pouch can reach the top of the anal canal better than $J$ pouch and thus construction of $\mathrm{S}$ pouch is obligatory in certain situations. ${ }^{24}$ In this condition, the shortest possible efferent limb should be constructed to avoid emptying problems.
Johnston et al. ${ }^{25}$ stated that the extra time and effort invested in the construction of a capacious, quadruplicated (W) reservoir by laborious hand suturing have not been repaid by any significant advantage in terms of overall bowel function when the results are compared with those provided by a comparatively small, duplicated $(\mathbf{J})$ reservoir, which is simple to construct with the aid of linear stapling instruments.

We noticed that evacuation of the pouch was positively correlated with the pouch anal angle; the more obtuse the pouch anal angles during rest and straining, the more efficient the pouch evacuation. An obtuse pouch anal angle is essentially associated with a vertical lie of the pouch in the pelvis. In such circumstances, the intra-abdominal pressure that is generated during straining will probably be dissipated in the proper direction to expel the feces out, rather than when the pouch lies obliquely and the pouch anal angle is more acute. The fact that the increment in pouch anal angle during straining was also significantly correlated with the efficiency of evacuation implies that a mobile angle that increased significantly during straining was behaving more like a normal recto anal angle during straining. A mobile angle is probably associated with less perianastomotic fibrosis, which essentially accompanies perianastomotic sepsis and/or excessive dissection in this area. We thus stress on the importance of adopting proper anastomotic technique to avoid leakage and sepsis and not to do excessive dissection at the top of the anal canal to achieve a sound, mobile pouch anal anastomosis that is essential for proper emptying.

In conclusion, the restorative proctocolectomy with $\mathrm{J}$ pouch ileoanal anastomosis confers good functional results to patients with ulcerative colitis in need of surgical treatment. This procedure is safe with minimal mortality and acceptable morbidity. It is the operation of choice for patients with UC because it removes the entire diseased colon with restoration of the intestinal continuity through an ileo anal anastomosis preserving fecal continence. Within 12-18 months, bowel frequency stabilizes at 6 bowel motions per day, with the majority of patients 
fully continent and able to postpone a bowel motion until convenient. Construction of the ileal pouch is the key to the success of this operation.

\section{References:}

1- Jess T, Loftus EV, Velayos FS, et al: Risk of intestinal cancer in inflammatory bowel disease: A population-based study from Olmsted country, Minnesota. Gastroenterology 2006; 130: 1039-1046.

2- Delaney CP, Fazio VW, Remzi FH, et al: prospective, age-related analysis of surgical results, functional outcomes, and quality of life after ileal pouch-anal anastomosis. Ann Surg 2003; 238: 221-228.

3- Stonington CM, Philips SF, Melton LJ, et al: Chronic ulcerative colitis: Incidence and prevalence in a community. Gut 1987 ; 28: 402-409.

4- Hahnloser D, Pemberton JH, Wolff BG, et al: Results up to 20 years after ileal pouchanal anastomosis for chronic ulcerative colitis. Br J Surg 2007; 94: 333-340.

5- Parc Y, Piquard A, Dozois RR, et al: Longterm outcome of familial adenomatous polyposis patients after restorative coloproectectomy. Ann Surg 2004; 239: 378-382.

6- Larson DW and Pemberton JH: Current concepts and controversies in surgery for IBD. Gastroenterology 2004; 126: 16111619.

7- Faruk P, Pemberton HJ, Wolff BG, et al: Functional outcomes after ileal pouch-anal anastomosis for chronic ulcerative colitis. Ann Surg 2000; 231(6): 919-926.

8- Baixauli J, Delaney CP, Wu JS, et al: Functional outcome and quality of life after repeat ileal pouch-anal anastomosis for complications of ileoanal surgery. Dis Colon Rectum 2004; 47(1): 2-11.

9- Wutbrich P, Gervaz P, Ambrosetti P, et al: Functional outcome and quality of life after restorative proctocolectomy and ileo-anal pouch anastomosis. Swiss Med Wkly 2009; 139(13-14): 193-197.

10-Marc Ferrante, Declerck S, Hertogh GD, et al: Outcome after proctocolectomy with ileal pouch-anal anastomosis for ulcerative colitis. Inflammatory Bowel Diseases 2008; 14(1): 20-28.
11-Gina K, Richard E, Henry S, et al: Comparison of outcomes after restorative proctocolectomy with or without defunctioning ileostomy. Arch Surg 2008; 143(4): 406-412.

12-Hueting WE, Buskens E, van der Tweel I, et al: Results and complications after ileal pouch anal anastomosis: a meta-analysis of 43 observational studies comprising 9317 patients. Dig Surg 2005; 22: 69-79.

13-Shen B, Achkar JP, Lashner BA, et al: Endoscopic and histological evaluation together with symptom assessment are required to diagnose pouchitis. Gastroenterology 2001; 121(2):261-267.

14-Abdelrazeq AS, Lund JN and Leveason SH: Implications of pouchitis on the functional results following stapled restorative proctocolectomy. Dis Colon Rectum 2005; 48: 1700-1707.

15-Shen B, Fazio VW, Remzi FH, et al: Risk factors for diseases of ileal pouch-anal anastomosis after restorative proctocolectomy for ulcerative colitis. Clin Gastroenterol Hepatol 2006; 4: 81-89.

16-Gionchetti P, Amadini C, Rizzello F, et al: Diagnosis and treatment of pouchitis. Best Pract Res Clin Gastroenterology 2003; 17(1): 75-87.

17-Michelassi F, Lee J, Rubin M, et al: Longterm functional results after ileal pouch anal restorative proctocolectomy for ulcerative colitis. Ann Surg 2003; 238(3): 433-445.

18-Mathis KL, Dozois EJ, Larson DW, et al: Outcomes in patents with ulcerative colitis undergoing partial or complete reconstructive surgery for failing ileal pouch-anal anastomosis. Ann Surg 2009; 249(3): 409-413.

19-Robb B, Pritts T, Gang G, et al: Quality of life in patients undergoing ileal pouch-anal anastomosis at the University of Cincinnati. Am J Surg 2002; 183(4):353-360.

20-Gullberg K and Liljeqvist L: Stapled ileoanal pouch without loop ileostomy: A prospective study in 86 patients. Int $J$ Colorectal Dis 2001; 16(4): 221-227.

21-Grofine SR, Fichera A, Harris MT, et al: Long-term results of salvage surgery for septic complications after restorative proctocolectomy: Does fecal diversion 
improve outcome? Dis colon Rectum 2003; 46(10): 1339-1344.

22-Tjandra JJ, Fazio VW, Milsom JW, et al: Omission of temporary diversion in Restorative proctocolectomy-is it safe? Dis Colon Rectum 1993; 36(11): 1007-1014.

23-Nasmyth DG, Johnston D, Godwin PGR, et al: Factors influencing bowel function after ileal pouch-anal anastomosis. $\mathrm{Br} J$ Surg 1986; 73: 469-473.
24-Keighley MRB and Williams NS: Surgery of the anus, rectum and colon. WB Saunders (Publisher); 1st edn. 1993; 12391591.

25-Johnston D, Williamson MER, Lewis WG et al: Prospective controlled trial of duplicated (J) versus quadruplicated (W) pelvic ileal reservoirs in restorative proctocolectomy for ulcerative colitis. Gut 1996; 39: 242-247. 